\title{
Estimating causal associations of atopic dermatitis with depression using the propensity score method: an analysis of Korea Community Health Survey data, 2010-2013
}

\author{
Hayon Michelle Choi, Dahye Kim, Whanhee Lee, Ho Kim \\ Graduate School of Public Health, Seoul National University, Seoul, Korea
}

OBJECTIVES: Numerous studies have reported associations between atopic dermatitis (AD) and depression, but the causal relationship between the 2 diseases has not been established. Therefore, this study used the propensity score method to investigate whether there was a positive causal effect of $\mathrm{AD}$ on depression in 16 regions (cities and provinces) in Korea.

METHODS: The study analyzed 16 regions (cities and provinces) in Korea, using data obtained from the Korea Community Health Survey for the years 2010-2013. Propensity score matching was used to estimate the causal influence of AD on depression in Korea.

RESULTS: After propensity score matching, the standardized difference for each covariate among the 16 regions (cities and provinces) was less than 1 , indicating a balance between the case and control groups. At the national level, those diagnosed with $\mathrm{AD}$ had a 2.31 times higher risk for being diagnosed with depression than those who had not been diagnosed with AD. In particular, the risk was highest in North Jeolla Province (odds ratio [OR], 4.87; 95\% confidence interval [CI], 2.28 to 10.43) and lowest in Gwangju (OR, 1.82; 95\% CI, 0.87 to 3.79), and the OR for Seoul was 2.23 (95\% CI, 1.66 to 2.99).

CONCLUSIONS: This study provides insights into how causal inferences can be derived from observational studies, through an analysis of Korea Community Health Survey data. Furthermore, the study results have implications for region-specific guidelines for preventive health policies targeting depression.

KEY WORDS: Atopic dermatitis, Depression, Epidemiology, Propensity score

\section{INTRODUCTION}

Atopic dermatitis (AD) is an inflammation of the skin accompanied by itchiness, and numerous studies conducted throughout

\section{Correspondence: Ho Kim}

Graduate School of Public Health, Seoul National University,

1 Gwanak-ro, Gwanak-gu, Seoul 08826, Korea

E-mail: hokim@snu.ac.kr

Received: Sep 18, 2018 / Accepted: Nov 29, 2018 / Published: Nov 29, 2018

This article is available from: http://e-epih.org/

(C) This is an open-access article distributed under the terms of the Creative Commons Attribution License (http://creativecommons.org/licenses/by/4.0/), which permits unrestricted use, distribution, and reproduction in any medium, provided the original work is properly cited.

(C) 2018, Korean Society of Epidemiology the world have reported $\mathrm{AD}$ to be associated with depression [15]. A study conducted in Taiwan among adolescents and adults with $\mathrm{AD}$ found a positive association between $\mathrm{AD}$ and depression in both groups, although the risk of $\mathrm{AD}$ for depression was higher among adults than among adolescents [1]. Furthermore, a study of $257 \mathrm{AD}$ patients in the US found a significant association between the severity of $\mathrm{AD}$ and depression [6]. Studies reporting an association between $\mathrm{AD}$ and depression in Korea have also been published [7-9]. A study using Korea Community Health Survey (KCHS) data from 2008 to 2013 presented a 1.33 times (95\% confidence interval [CI], 1.02 to 1.74) higher risk of depression in $\mathrm{AD}$ patients than in non-AD patients [9]. Furthermore, adolescents with $\mathrm{AD}$ were 1.27 times more likely to experience depression symptoms [7]. The prevalence of both depression and $\mathrm{AD}$ is increasing in Korea [10,11]; therefore estimating the risk of $\mathrm{AD}$ for 
depression is required, along with an analysis of suitable medical and health policies.

Most observational investigations have shown statistically significant associations between $\mathrm{AD}$ and depression, although few studies have sought to characterize the causal relationship between these 2 diseases [12]. The symptoms of $\mathrm{AD}$ (itchiness, aches, etc.) cause a lack of sleep and difficulties concentrating [13], leading to stress in social relationships [14,15]. In particular, numerous cytokines and immune cells are involved in the pathogenesis of $\mathrm{AD}$ and might interact with factors influencing sleep [16]. These results of biological and social studies support the causal effect of $\mathrm{AD}$ on depression. However, in observational studies, selection bias occurs and the distribution of covariates among the exposed and unexposed groups is not homogeneous since the measured variables cannot be controlled. The heterogeneity of covariates between 2 groups limits the ability to draw causal inferences [17-20]. To overcome these limitations of observational studies, randomized clinical trials (RCTs) and cohort studies are conducted to estimate causal associations. Nevertheless, such designs are not suitable for large-scale epidemiological studies due to their high costs and difficulties with sampling [21,22].

Several methods have been proposed to overcome selection bias in observational studies $[19,23,24]$. Among those methods, the most commonly used is propensity score matching (PSM) [18]. The propensity score is the conditional probability that an individual will belong to the exposed group when a specific covariate value is given [18]. In PSM, study subjects who are matched by the levels of covariates affecting the results are assigned to exposed and unexposed groups. This method is similar to an RCT, in that randomly assigning differences in covariance between the exposed and unexposed groups minimizes selection bias in observational studies [17]. Furthermore, PSM can be conducted not only in observational studies, but also in retrospective studies, for which random assignment is difficult [25]. Thus, our study aimed to estimate the causal association between $\mathrm{AD}$ and depression diagnoses using the PSM approach.

\section{MATERIALS AND METHODS}

\section{Data}

We analyzed data from the KCHS during 2010-2013 for 16 regions (cities and provinces ) in Korea [20]. The KCHS was organized by the Korea Centers for Disease Control and Prevention [26]. Data were collected from adults more than 19 years old through interviews. First, the samples for the KCHS were selected from an average of 900 adults per region (city, county, district) based on the housing type for each township, neighborhood, and town. Probability proportional to size systematic sampling was used for the first sample region, and then the sample families were selected as the secondary sample region [27]. A total of 917,948 people were included in the KCHS data used in this study (2010: 230,712; 2011: $229,229 ; 2012: 229,226 ; 2013: 228,781)$. Using the data, we calculated participants' body mass index (BMI), and used self-reported data for level of education, current smoking status, current drinking status, preference for low sodium intake, diagnosis of $\mathrm{AD}$, and diagnosis of depression.

\section{Statistical analysis}

PSM was used to estimate the causal association between $\mathrm{AD}$ and depression [28]. The outcome was the self-reported diagnosis of depression by a doctor at any point in the respondent's lifetime. The subjects were asked "Have you ever been diagnosed with depression by a doctor?". The exposure variable was a self-reported $\mathrm{AD}$ diagnosis, which was obtained by asking the subjects "Have you ever been diagnosed with $\mathrm{AD}$ by a doctor?". Eight other covariates were considered (age, sex, current smoking status, current drinking status, preference for low sodium intake, BMI, and year). To take into account the time trend of depression diagnoses, an indicator variable for time was added [29]. The study utilized a 3-stage analysis.

\section{First stage: propensity score matching}

For the composite sample design of the KCHS, a logistic propensity model considering weighting, stratification, and cluster variables is shown in equation (1).

$$
\log \frac{\mathrm{P}\left(\mathrm{Z}=1 \mid x_{1}, x_{2}, \ldots, x_{p}\right)}{\mathrm{P}\left(\mathrm{Z}=0 \mid x_{1}, x_{2}, \ldots, x_{p}\right)}=\beta_{0}+\sum_{t=1}^{p} \beta_{t} x_{t}
$$

$\mathrm{AD}$ diagnosis is indicated as $\mathrm{Z}(\mathrm{Z}=1$ when diagnosed with $\mathrm{AD}$ [case], $\mathrm{Z}=0$ when not diagnosed with $\mathrm{AD}$ [control]), and $x_{t}$ indicates covariates. Using the following equation, the propensity score was calculated. The propensity score could be expressed as equation (2).

$$
\begin{aligned}
\widehat{\mathrm{P}}\left(\mathrm{Z}=1 \mid x_{1}, x_{2}, \ldots, x_{p}\right) & =\frac{\exp \left(\hat{\beta}_{0}+\sum_{t=1}^{p} \widehat{\beta_{t}} x_{t}\right)}{1+\exp \left(\hat{\beta}_{0}+\sum_{t=1}^{p} \widehat{\beta}_{t} x_{t}\right)} \\
& =(\text { propensity score })
\end{aligned}
$$

Based on the propensity score from equation (2), each case was matched at a 1:1 ratio with the control with the closest propensity score. Specifically, the caliper method matches each case with 1 control within a certain logit propensity score (log $\frac{\text { (propensity score) }}{1-\text { (propensity score) })}$ range, which is generally defined as 0.2 times the standard deviation of the propensity score [30,31]. In this study, a 0.28 caliper range was used in the analysis. The first-stage analysis was conducted using SAS version 9.4 (SAS Institute Inc., Cary, NC, USA).

\section{Second stage: conditional logistic regression}

$$
\operatorname{clogit}\left(P_{i}\right)=\tau_{0 i}+\gamma_{i} Z_{i}, i=1,2,3, \ldots 15,16
$$

In the second stage, a conditional logistic regression model was fitted to each region using the 1:1 matched data from the first stage. The conditional logistic regression analysis was conducted using the Breslow method. $\gamma_{i}$ is the region with the ith coefficient of the AD diagnosis $\left(Z_{i}\right)$, and $P_{i}$ is the expected probability that the sub- 
ject will have depression in region $i$.

\section{Third stage: meta-analysis}

$$
W_{i}=\mu+\xi_{i}+\varepsilon_{i}, \quad i=1,2,3, \ldots 15,16
$$

A random-effect multivariate meta-analysis was computed, as shown in equation (4). The observed effect $\left(W_{i}\right)$ was expressed as the true variation in the effect size $\left(\xi_{i}\right)$, summary effect $(\mu)$, and the sampling error $\left(\varepsilon_{i}\right)$. $\xi_{i}$ is the distance between the effect for each 16 coefficients of the AD diagnosis $\left(\gamma_{i}\right)$. Furthermore, the region population was considered as the weight in the third stage. The causal association of $\mathrm{AD}$ on depression diagnosis was expressed in terms of ORs. The second and third stages of the analysis were performed using R version 3.4.2 (https://cran.r-project.org/ bin/windows/base/old/3.4.2/) and the R package metaphor [32]. For a sensitivity analysis, we applied different propensity methods, including stratification, propensity score adjustment as a covariate, and weighting. In stratification, subjects are grouped into mutually exclusive subsets by the propensity score, resulting in a similar propensity score within each stratum between the exposed and unexposed subjects. A widely used approach in stratification is to divide subjects into 5 equal-size quintiles [33]. In covariate adjustment, the developed propensity score is assumed as a predictor variable. This separate multivariable regression model estimates the outcome, while adjusting for the probability that a subject belongs to the exposed group. For weighting, the inverse probability of treatment weighting using the propensity score was employed. This concept corresponds to survey sampling weights, which make a sample representative of a specific population [34].

\section{RESULTS}

Table 1 presents the overall descriptive statistics according to $\mathrm{AD}$ diagnosis before and after PSM. Before PSM, there were 895,046 subjects not diagnosed with $\mathrm{AD}$ and 21,111 diagnosed with $\mathrm{AD}$. After PSM, there were 21,111 subjects in both groups. The distribution of covariates between cases (AD diagnosis) and controls (no AD diagnosis) after PSM was similar. Of the controls, 65.3\% were current drinkers before PSM, and after PSM the proportion was $26.7 \%$, which was identical to the proportion of current drinkers among cases (26.7\%). Furthermore, the standardized difference in each covariate sharply decreased after PSM, from 2.1954.56 to $0.01-0.22$. The $\mathrm{p}$-value of the chi-square test for the stand-

Table 1. Descriptive statistics and standardized differences for individuals with and without AD, before and after PSM

\begin{tabular}{|c|c|c|c|c|c|c|}
\hline \multirow{2}{*}{ Variables } & & \multicolumn{2}{|c|}{ No AD } & \multirow{2}{*}{$\begin{array}{c}A D \\
(n=21,111)\end{array}$} & \multicolumn{2}{|c|}{ Standardized difference } \\
\hline & & Before PSM $(n=895,046)$ & After PSM $(n=21,111)$ & & Before PSM & After PSM \\
\hline Age (yr) & & $51.4 \pm 16.8$ & $42.2 \pm 17.9$ & $41.8 \pm 17.8$ & 54.56 & 0.22 \\
\hline \multirow[t]{2}{*}{ Sex } & Male & $404,596(45.2)$ & $8,634(40.9)$ & $8,616(40.8)$ & 9.79 & 0.14 \\
\hline & Female & $490,450(54.8)$ & $12,477(59.9)$ & $12,495(59.2)$ & - & - \\
\hline BMI $\left(\mathrm{kg} / \mathrm{m}^{2}\right)$ & & $22.9 \pm 3.4$ & $22.4 \pm 3.1$ & $22.6 \pm 3.4$ & 6.87 & 0.01 \\
\hline \multirow[t]{7}{*}{ Education level } & No education & $73,450(8.2)$ & $902(4.3)$ & $802(3.8)$ & 41.13 & 0.27 \\
\hline & Preschool & $2,483(0.3)$ & $17(0.1)$ & $34(0.2)$ & - & - \\
\hline & Elementary school & $164,484(18.3)$ & $2,342(11.1)$ & $2,301(10.9)$ & - & - \\
\hline & Middle school & $104,443(11.7)$ & $1,598(7.6)$ & $1,603(7.6)$ & - & - \\
\hline & High school & $260,909(29.1)$ & $5,286(25.0)$ & $5,364(25.4)$ & - & - \\
\hline & $2-3$ years of college & $91,958(10.3)$ & $3,319(16.1)$ & $3,391(16.1)$ & - & - \\
\hline & 4 years of university & $169,648(18.9)$ & $6,884(32.6)$ & $6,688(31.7)$ & - & - \\
\hline \multirow[t]{2}{*}{ Current drinking } & Yes & $584,163(65.3)$ & $5,557(26.7)$ & $5,640(26.7)$ & 16.43 & 0.02 \\
\hline & No & $310,883(34.7)$ & $15,554(73.3)$ & $15,471(73.3)$ & - & - \\
\hline \multirow[t]{2}{*}{ Current smoking } & Yes & $175,772(19.6)$ & $3,643(17.3)$ & $3,999(18.9)$ & 2.19 & 0.15 \\
\hline & No & $719,274(80.4)$ & $17,469(82.7)$ & $17,112(8.1)$ & - & - \\
\hline \multirow[t]{5}{*}{ Sodium intake } & Very high & $8,119(0.9)$ & $247(1.2)$ & $318(1.5)$ & 7.38 & 0.16 \\
\hline & High & $228,121(25.5)$ & $6,411(30.4)$ & $6,424(30.4)$ & - & - \\
\hline & Moderate & $453,192(50.6)$ & $9,678(45.8)$ & $9,405(44.6)$ & - & - \\
\hline & Low & $185,801(20.8)$ & $4,409(20.9)$ & $4,437(21.0)$ & - & - \\
\hline & Very low & $19,634(2.2)$ & $364(1.7)$ & $521(2.5)$ & - & - \\
\hline \multirow[t]{2}{*}{ Depression } & Yes & $21,788(2.4)$ & $427(2.0)$ & $1,063(5.0)$ & - & - \\
\hline & No & $873,258(97.6)$ & $20,684(98.0)$ & $20,048(95.0)$ & - & - \\
\hline$p$-value ${ }^{1}$ & & & & & $<0.001$ & 0.42 \\
\hline
\end{tabular}

Values are presented as mean \pm standard deviation or number (\%).

$A D$, atopic dermatitis; PSM, propensity score matching.

'Using the chi-square test for the standardized difference of covariate means. 
ardized difference is shown below in Table 1. The findings accepted the null hypothesis that there would be no differences between cases and controls after PSM $(\mathrm{p}=0.42)\left(\mathrm{H}_{0}\right.$ : the difference between the two groups is zero). Supplementary Material 1 presents descriptive statistics for each of the 16 cities and provinces.

Figure 1 is a national map representing the standardized prevalence of $\mathrm{AD}$ and depression diagnoses considering the sampling weight. AD diagnoses in all administrative subunits of Seoul showed the highest prevalence (2.72-4.74\%), while the lowest prevalence was found in South Jeolla Province (0.47-2.73\%). The prevalence of $\mathrm{AD}$ diagnoses tended to be higher in metropolitan areas (Seoul, Gyeonggi Province). The prevalence of depression diagnoses was highest in Jeju Province (2.15-3.21\%) and lowest in Ulsan (1.23-2.27\%). The prevalence of depression diagnoses showed wide geographical variation across the country. The prevalence of $\mathrm{AD}$ and depression diagnoses in the 253 administrative divisions of Korea ar all administrative subunits level is demonstrated in Supplementary Material 2.

The risk of receiving a depression diagnosis among those with an $\mathrm{AD}$ diagnosis in the 16 cities and provinces before and after PSM is presented as ORs in Table 2 and Figure 2. After PSM, people in Korea with an AD diagnosis were 2.31 times (95\% CI, 1.92 to 2.76) more likely to have been diagnosed with depression. The risk was highest in North Jeolla Province (OR, 4.87; 95\% CI, 2.28 to 10.43 ) and lowest in Gwangju (OR, 1.82; 95\% CI, 0.87 to 3.79). The risk also differed by region based on the use of PSM; people diagnosed with $\mathrm{AD}$ were 2.23 times (95\% CI, 1.66 to 2.99 ) more likely to have received a depression diagnosis when using PSM, while the risk was 2.26 (95\% CI, 1.67 to 3.05) before PSM.

The ORs when using stratification, covariate adjustment, and the propensity score weighting method are shown in Table 3 . When stratification was used, the propensity score within the first to fifth quartiles had ORs with a range of 1.88-2.47. The OR was $2.36(95 \%$

Table 2. ORs before and after PSM

\begin{tabular}{lcc}
\hline Region & Before PSM & After PSM \\
\hline Seoul & $2.26(1.67,3.05)$ & $2.23(1.66,2.99)$ \\
Busan & $2.39(1.54,3.72)$ & $1.94(1.26,2.97)$ \\
Daegu & $2.37(1.14,4.96)$ & $3.20(1.57,6.51)$ \\
Incheon & $2.50(1.37,4.54)$ & $3.07(1.71,5.49)$ \\
Gwangju & $2.45(1.14,5.27)$ & $1.82(0.87,3.79)$ \\
Daejeon & $2.07(0.99,4.30)$ & $2.08(1.07,4.03)$ \\
Ulsan & $3.67(1.38,9.80)$ & $2.67(1.04,6.81)$ \\
Gyeonggi Province & $2.42(1.88,3.11)$ & $2.88(2.26,3.69)$ \\
Gangwon Province & $2.54(1.61,4.01)$ & $2.50(1.61,3.88)$ \\
North Chungcheong Province & $3.76(2.29,6.19)$ & $2.21(1.36,3.58)$ \\
South Chungcheong Province & $1.95(1.19,3.20)$ & $2.17(1.34,3.51)$ \\
North Jeolla Province & $1.89(0.86,4.16)$ & $4.87(2.28,10.43)$ \\
South Jeolla Province & $2.41(1.46,4.00)$ & $2.00(1.23,3.26)$ \\
North Gyeongsang Province & $2.11(1.37,3.23)$ & $2.09(1.38,3.17)$ \\
South Gyeongsang Province & $3.20(1.76,5.80)$ & $4.14(2.31,7.43)$ \\
Jeju Province & $2.97(1.39,6.35)$ & $2.09(1.02,4.29)$ \\
Total & $2.35(1.44,3.83)$ & $2.31(1.92,2.76)$ \\
\hline
\end{tabular}

Values are presented as OR (95\% confidence interval).

$\mathrm{OR}$, odds ratio; PSM, propensity score matching.
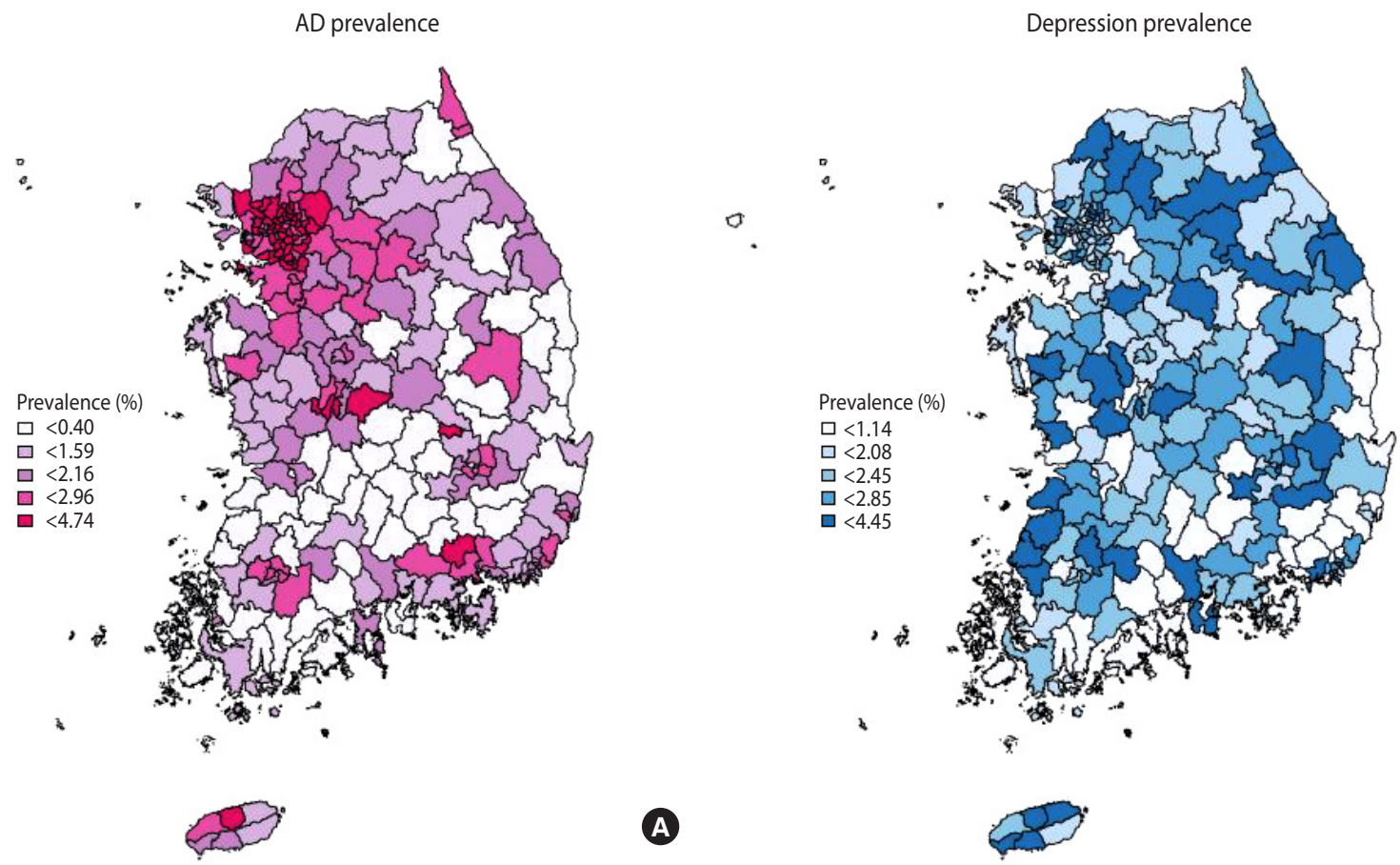

Figure 1. Geographical distribution of the prevalence of $(A)$ atopic dermatitis $(A D)$ and $(B)$ depression diagnoses. 


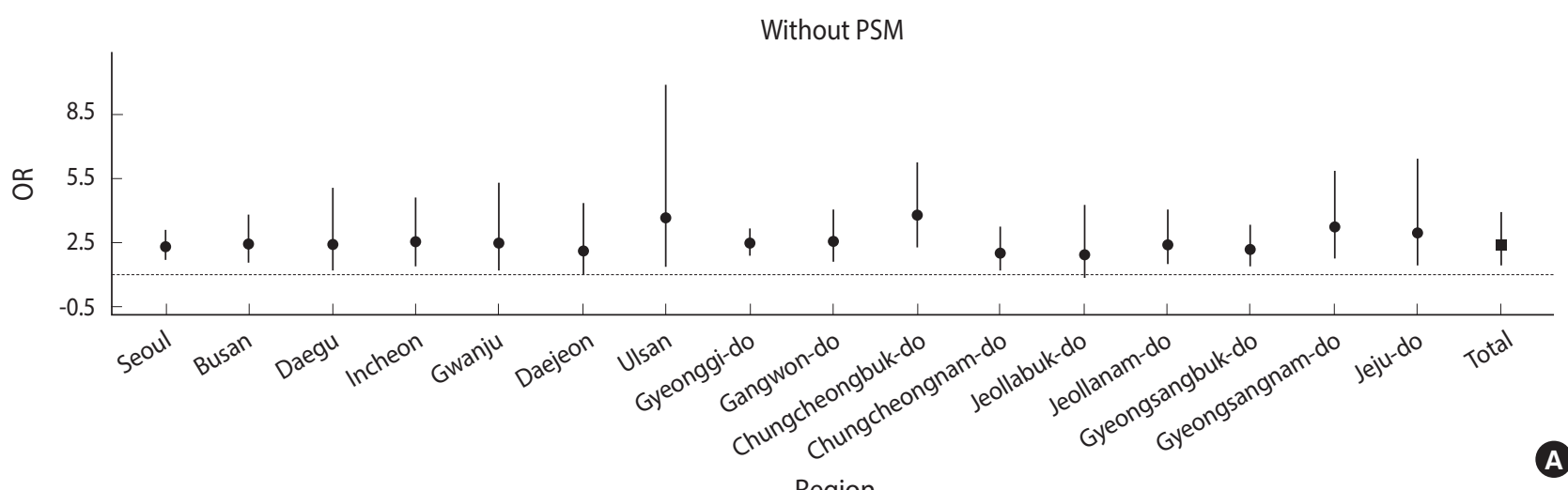

Region

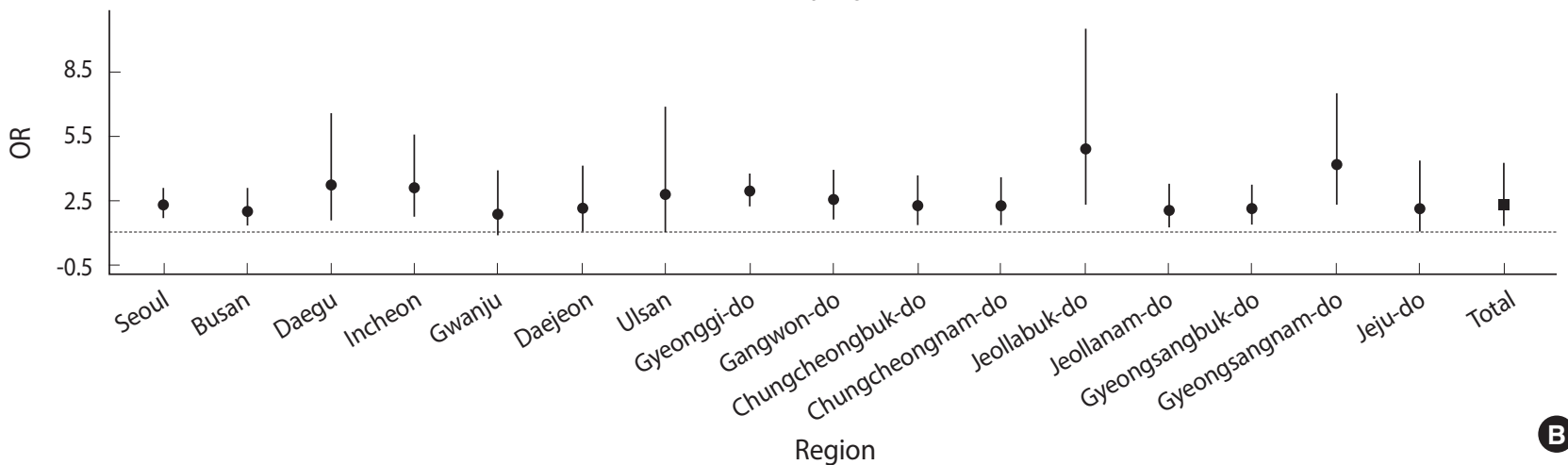

Figure 2. Odds ratios (ORs) from the meta-analysis (A) without propensity score matching (PSM) and (B) with PSM.

CI, 1.48 to 3.74 ) using covariate adjustment, and 2.38 (95\% CI, 1.28 to 4.42 ) using the weighting method. These findings were similar to the OR of 2.38 obtained using PSM.

\section{DISCUSSION}

This study estimated the causal effect of AD on depression diagnosis using data from the KCHS. Before PSM, each covariate ratio was unbalanced, but the covariates became balanced after PSM (overall p-value $=0.42$ ). In this analysis using PSM to conduct an analysis of 16 regions in Korea, it was found that individuals diagnosed with $\mathrm{AD}$ had a 2.31 times (95\% CI, 1.92 to 2.76) higher risk of having been diagnosed with depression than their counterparts.

Several studies have documented biological mechanisms through which $\mathrm{AD}$ may influence the likelihood of a depression diagnosis [35-38]. Depression is associated with changes in the immune system [39-42], and immunoglobulin E (IgE)-mediated allergies are more common in depression patients than other allergies [35]. Since AD is an IgE-mediated disease [43], AD patients are likely to have more severe depression symptoms $[37,38]$. Thus, immune mediators, such as cytokines, are involved in the mechanism underlying both $\mathrm{AD}$ and depression [44-47]. Cytokines mediate the chemical communications between the immune system and the brain [48]. In $\mathrm{AD}$, the cytokine interleukin-4 affects serotonin (5HT) metabolism [47]. Specifically, 5-HT is an essential mediator of both the nervous and the immune systems, and some aspects of the role of 5-HT in the body have been linked to depression [47]. Therefore, depression could be explained by changes in 5-HT metabolism during $\mathrm{AD}$ [49].

Studies have reported that $\mathrm{AD}$ is closely related to depression, and may actually be an underlying cause of depression. Considering demographic, socioeconomic, and clinical characteristics, 1:5matched PSM was conducted using KCHS data from 2007-2012 [8]. The results showed a 1.36 times higher risk of depression in $\mathrm{AD}$ patients. Another study in Korea among adolescents demonstrated that $\mathrm{AD}$ was associated with an $\mathrm{OR}$ for depression of 1.28 (95\% CI, 1.20 to 1.37), an OR of suicidal thoughts of 1.31 (95\% CI, 1.21 to 1.42), an OR of suicidal planning of 1.42 (95\% CI, 1.26 to 1.61 ), and an OR for suicide attempt of 1.51 (95\% CI, 1.32 to 1.73) [7].

This study has some strengths. First, it estimated the causal association between these 2 variables by adjusting for the confounding factors in an observational study setting. When attempting to characterize a causal relationship, it is difficult to arrive at an estimate using methods other than an RCT. However, RCTs have limitations in terms of time, ethical issues, and costs; thus, many studies are based on observational data, for which PSM could be a 


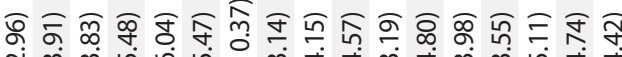
nั0

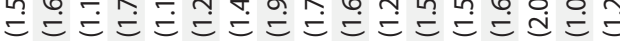

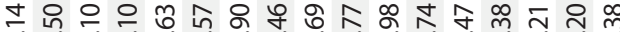
i

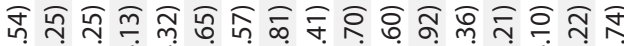
\& "

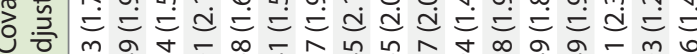

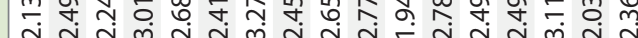

क

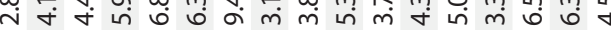

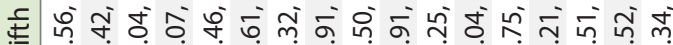

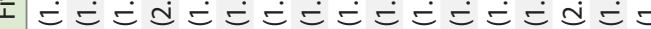

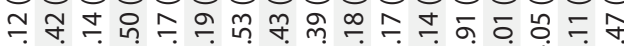

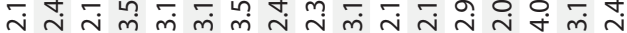

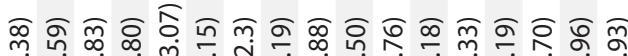
m mơ

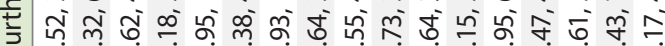

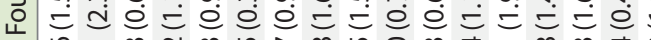

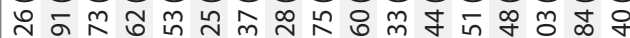

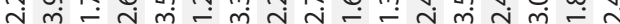

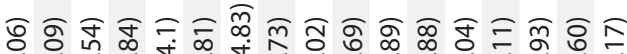
$m$ in 0 U

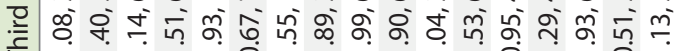

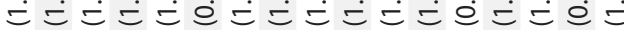
๙ 宓

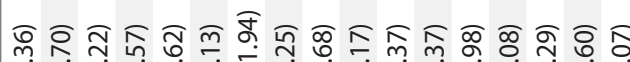

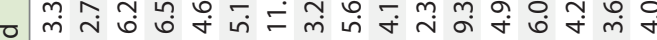

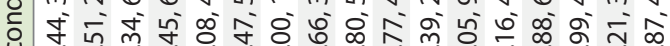

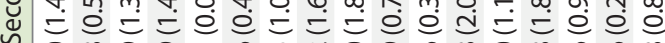

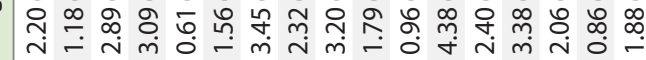

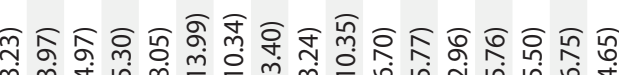
๘ it ○ \& ᄋ ळ ji-

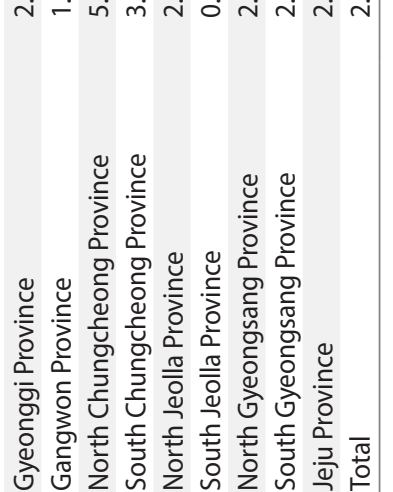

practical method, such as in this study. Second, this study considered the local characteristics of the 16 regions. When calculating the propensity score, the stratification variables, cluster variables, and weights were considered in order to reflect the KCHS questionnaire design. We also reduced discrepancies between regions by weighting each population while deriving the overall risk. Third, this study presented findings on the causal association between $\mathrm{AD}$ and depression in Korea. Even though studies have shown associations between $\mathrm{AD}$ and depression, few studies have estimated the causal effect of AD on depression in Korea. Furthermore, this study presented several results obtained using propensity score methods for 16 regions.

There are some inherent limitations of the propensity score method. When calculating the propensity score, all covariates used in the analysis should not have missing values. Since considering all covariates is problematic, the ability to characterize the causal relationship perfectly is limited. Furthermore, the propensity score method is a statistical method that cannot alter the fundamental research design. Moreover, since there could be an association between spatial clustering and the disease incidence, further studies should be conducted using spatial clustering analysis.

This study proposed a causal effect of $\mathrm{AD}$ on depression diagnosis using data from the KCHS, and suggested ideas and methods for estimating causal associations based on an observational study. Our study results make an implication for preventive health interventions targeted toward $\mathrm{AD}$ patients at risk for depression and geographical areas vulnerable to $\mathrm{AD}$.

\section{ACKNOWLEDGEMENTS}

This work was supported by the Korea Ministry of Environment through the Climate Change Correspondence Program (grant no. 20140013 10007).

\section{CONFLICT OF INTEREST}

The authors have no conflicts of interest to declare for this study.

\section{SUPPLEMENTARY MATERIALS}

Supplementary Material 1: Table S1 is available at http://www.eepih.org/.

Supplementary Material 2: Table S2 is available at http://www.eepih.org/.

\section{ORCID}

Hayon Michelle Choi: $h t t p: / / o r c i d . o r g / 0000-0002-0622-8554$; Dahye Kim: http://orcid.org/0000-0001-8554-7555; Whanhee Lee: http://orcid.org/0000-0001-5723-9061; Ho Kim: http://orcid.org/ 0000-0001-7472-3752 


\section{REFERENCES}

1. Cheng CM, Hsu JW, Huang KL, Bai YM, Su TP, Li CT, et al. Risk of developing major depressive disorder and anxiety disorders among adolescents and adults with atopic dermatitis: a nationwide longitudinal study. J Affect Disord 2015;178:60-65.

2. Yaghmaie P, Koudelka CW, Simpson EL. Mental health comorbidity in patients with atopic dermatitis. J Allergy Clin Immunol 2013;131:428-433.

3. Slattery MJ, Essex MJ, Paletz EM, Vanness ER, Infante M, Rogers GM, et al. Depression, anxiety, and dermatologic quality of life in adolescents with atopic dermatitis. J Allergy Clin Immunol 2011; 128:668-671.

4. Yu SH, Silverberg JI. Association between atopic dermatitis and depression in US adults. J Invest Dermatol 2015;135:3183-3186.

5. Kiebert G, Sorensen SV, Revicki D, Fagan SC, Doyle JJ, Cohen J, et al. Atopic dermatitis is associated with a decrement in healthrelated quality of life. Int J Dermatol 2002;41:151-158.

6. Mancuso CA, Wenderoth S, Westermann H, Choi TN, Briggs WM, Charlson ME. Patient-reported and physician-reported depressive conditions in relation to asthma severity and control. Chest 2008;133:1142-1148.

7. Lee S, Shin A. Association of atopic dermatitis with depressive symptoms and suicidal behaviors among adolescents in Korea: the 2013 Korean Youth Risk Behavior Survey. BMC Psychiatry 2017;17:3.

8. Kim S, Lee JY, Oh JY, Chekal L, Lee DC. The association between atopic dermatitis and depressive symptoms in Korean adults: the fifth Korea National Health and Nutrition Examination Survey, 2007-2012. Korean J Fam Med 2015;36:261-265.

9. Kim KH, Park AY, Kim JS. Factors associated with atopic dermatitis in Korean adults: the Korean National Health and Nutrition Survey 2008. Korean J Rehabil Nurs 2012;15:83-90 (Korean).

10. Yu JS, Lee CJ, Lee HS, Kim J, Han Y, Ahn K, et al. Prevalence of atopic dermatitis in Korea: analysis by using national statistics. J Korean Med Sci 2012;27:681-685.

11. Park JH, Kim KW. A review of the epidemiology of depression in Korea. J Korean Med Assoc 2011;54:362-369 (Korean).

12. Park H, Kim K. Association of perceived stress with atopic dermatitis in adults: a population-based study in Korea. Int J Environ Res Public Health 2016;13:E760.

13. Dahl RE, Bernhisel-Broadbent J, Scanlon-Holdford S, Sampson HA, Lupo M. Sleep disturbances in children with atopic dermatitis. Arch Pediatr Adolesc Med 1995;149:856-860.

14. Howlett S. Emotional dysfunction, child-family relationships and childhood atopic dermatitis. Br J Dermatol 1999;140:381-384.

15. Carroll CL, Balkrishnan R, Feldman SR, Fleischer AB Jr, Manuel JC. The burden of atopic dermatitis: impact on the patient, family, and society. Pediatr Dermatol 2005;22:192-199.

16. Chang YS, Chiang BL. Mechanism of sleep disturbance in children with atopic dermatitis and the role of the circadian rhythm and melatonin. Int J Mol Sci 2016;17:462.

17. Lee DG. An introduction to propensity score matching methods.
Anesth Pain Med 2016;11:130-148 (Korean).

18. Pattanayak CW, Rubin DB, Zell ER. Propensity score methods for creating covariate balance in observational studies. Rev Esp Cardiol 2011;64:897-903.

19. Vyas S, Heise L. Using propensity score matching to estimate an "unbiased effect-size" between women's employment and partner violence in Tanzania. J Interpers Violence 2014;29:2971-2990.

20. Kim YT, Choi BY, Lee KO, Kim H, Chun JH, Kim SY, et al. Overview of Korean Community Health Survey. J Korean Med Assoc 2012;55:74-83 (Korean).

21. Levin KA. Study design IV: cohort studies. Evid Based Dent 2006; 7:51-52.

22. Levin KA. Study design VII. Randomised controlled trials. Evid Based Dent 2007;8:22-23.

23. Shahar E, Shahar DJ. Causal diagrams and the cross-sectional study. Clin Epidemiol 2013;5:57-65.

24. Sanderson S, Tatt ID, Higgins JP. Tools for assessing quality and susceptibility to bias in observational studies in epidemiology: a systematic review and annotated bibliography. Int J Epidemiol 2007;36:666-676.

25. Day AG. Why the propensity for propensity scores? Crit Care Med 2015;43:2024-2026.

26. Choi HM, Kim HC, Kang DR. Sex differences in hypertension prevalence and control: analysis of the 2010-2014 Korea National Health and Nutrition Examination Survey. PLoS One 2017;12: e0178334.

27. Lee WH, Choo JY, Son JY, Kim H. Association between long-term exposure to air pollutants and prevalence of cardiovascular disease in 108 South Korean communities in 2008-2010: a cross-sectional study. Sci Total Environ 2016;565:271-278.

28. Rosenbaum PR, Rubin DB. The central role of the propensity score in observational studies for causal effects. Biometrika 1983;70:4155.

29. Pannucci CJ, Wilkins EG. Identifying and avoiding bias in research. Plast Reconstr Surg 2010;126:619-625.

30. Austin PC. The performance of different propensity score methods for estimating marginal hazard ratios. Stat Med 2013;32:28372849.

31. Austin PC. Optimal caliper widths for propensity-score matching when estimating differences in means and differences in proportions in observational studies. Pharm Stat 2011;10:150-161.

32. Viechtbauer $\mathrm{W}$. Conducting meta-analyses in $\mathrm{R}$ with the metafor package. J Stat Softw 2010;36:1-48.

33. Cochran WG. The effectiveness of adjustment by subclassification in removing bias in observational studies. Biometrics 1968; 24:295-313.

34. Morgan SL, Todd JJ. A diagnostic routine for the detection of consequential heterogeneity of causal effects. Sociol Methodol 2008; 38:231-282.

35. Bell IR, Jasnoski ML, Kagan J, King DS. Depression and allergies: survey of a nonclinical population. Psychother Psychosom 1991; 55:24-31.

36. Centanni S, Di Marco F, Castagna F, Boveri B, Casanova F, Piazzini A. Psychological issues in the treatment of asthmatic patients. 
Respir Med 2000;94:742-749.

37. Eisner MD, Katz PP, Lactao G, Iribarren C. Impact of depressive symptoms on adult asthma outcomes. Ann Allergy Asthma Immunol 2005;94:566-574.

38. Hashiro M, Okumura M. The relationship between the psychological and immunological state in patients with atopic dermatitis. J Dermatol Sci 1998;16:231-235.

39. Herbert TB, Cohen S. Depression and immunity: a meta-analytic review. Psychol Bull 1993;113:472-486.

40. Gold SM, Irwin MR. Depression and immunity: inflammation and depressive symptoms in multiple sclerosis. Immunol Allergy Clin North Am 2009;29:309-320.

41. Miller GE, Cohen S, Herbert TB. Pathways linking major depression and immunity in ambulatory female patients. Psychosom Med 1999;61:850-860.

42. Olff M. Stress, depression and immunity: the role of defense and coping styles. Psychiatry Res 1999;85:7-15.

43. Galli SJ, Tsai M. IgE and mast cells in allergic disease. Nat Med
2012;18:693-704.

44. Dantzer R. Cytokine, sickness behavior, and depression. Immunol Allergy Clin North Am 2009;29:247-264.

45. Maes M. A review on the acute phase response in major depression. Rev Neurosci 1993;4:407-416.

46. Wamboldt MZ, Hewitt JK, Schmitz S, Wamboldt FS, Räsänen M, Koskenvuo M, et al. Familial association between allergic disorders and depression in adult Finnish twins. Am J Med Genet 2000; 96:146-153.

47. Mössner R, Daniel S, Schmitt A, Albert D, Lesch KP. Modulation of serotonin transporter function by interleukin-4. Life Sci 2001; 68:873-880.

48. Kronfol Z, Remick DG. Cytokines and the brain: implications for clinical psychiatry. Am J Psychiatry 2000;157:683-694.

49. Timonen M, Jokelainen J, Hakko H, Silvennoinen-Kassinen S, Meyer-Rochow VB, Herva A, et al. Atopy and depression: results from the Northern Finland 1966 birth cohort study. Mol Psychiatry $2003 ; 8: 738-744$. 